\title{
ORIGINAL ARTICLE Neuropilin-1 is upregulated in the adaptive response of prostate tumors to androgen-targeted therapies and is prognostic of metastatic progression and patient mortality
}

BWC Tse ${ }^{1,13}$, M Volpert ${ }^{1,13}$, E Ratther ${ }^{1,13}$, N Stylianou ${ }^{1}$, M Nouri ${ }^{2}, K_{\text {McGowan }}{ }^{1}$, ML Lehman ${ }^{1}$, SJ McPherson ${ }^{1}$, M Roshan-Moniri ${ }^{2}$, MS Butler ${ }^{2}$, J Caradec ${ }^{2}$, CY Gregory-Evans ${ }^{3}, \mathrm{~J} \mathrm{McGovern}^{4}$, R Das ${ }^{5}, \mathrm{M}$ Takhar $^{6}$, N Erho ${ }^{6}$, M Alshalafa ${ }^{6}$, E Davicioni ${ }^{6}$, EM Schaeffer $^{7}$, RB Jenkins ${ }^{8}$, AE Ross ${ }^{9}$, RJ Karnes ${ }^{10}$, RB Den ${ }^{11}$, L Fazli ${ }^{2}$, PA Gregory ${ }^{12}$, ME Gleave ${ }^{2}$, ED Williams ${ }^{1}$, PS Rennie ${ }^{2}$, R Buttyan $^{2}$, JH Gunter ${ }^{1}$, LA Selth $^{5}$, PJ Russell ${ }^{1}$, CC Nelson ${ }^{1}$ and BG Hollier ${ }^{1}$

Recent evidence has implicated the transmembrane co-receptor neuropilin-1 (NRP1) in cancer progression. Primarily known as a regulator of neuronal guidance and angiogenesis, NRP1 is also expressed in multiple human malignancies, where it promotes tumor angiogenesis. However, non-angiogenic roles of NRP1 in tumor progression remain poorly characterized. In this study, we define NRP1 as an androgen-repressed gene whose expression is elevated during the adaptation of prostate tumors to androgentargeted therapies (ATTs), and subsequent progression to metastatic castration-resistant prostate cancer (mCRPC). Using short hairpin RNA (shRNA)-mediated suppression of NRP1, we demonstrate that NRP1 regulates the mesenchymal phenotype of mCRPC cell models and the invasive and metastatic dissemination of tumor cells in vivo. In patients, immunohistochemical staining of tissue microarrays and mRNA expression analyses revealed a positive association between NRP1 expression and increasing Gleason grade, pathological T score, positive lymph node status and primary therapy failure. Furthermore, multivariate analysis of several large clinical prostate cancer (PCa) cohorts identified NRP1 expression at radical prostatectomy as an independent prognostic biomarker of biochemical recurrence after radiation therapy, metastasis and cancer-specific mortality. This study identifies NRP1 for the first time as a novel androgen-suppressed gene upregulated during the adaptive response of prostate tumors to ATTs and a prognostic biomarker of clinical metastasis and lethal PCa.

Oncogene (2017) 36, 3417-3427; doi:10.1038/onc.2016.482; published online 16 January 2017

\section{INTRODUCTION}

Prostate cancer (PCa)-associated mortality is due to therapyresistant metastatic tumor burden. Although prostate-confined tumors are often treatable by surgery and/or radiation, distal metastatic disease remains incurable. Local recurrence following radical prostatectomy $(\mathrm{RP})$ can be treated by salvage radiation therapy. However, this approach fails in some patients if tumor cells acquire radiation resistance, or if undetected (occult) distal metastases have already formed at the time of radiotherapy. Once metastatic disease is established, treatment relies on androgentargeted therapies (ATTs), which exploit the androgen dependence of PCa cells. Although ATTs provide a temporary remission (usually 2-3 years), they inevitably promote adaptation of tumor cells to low androgen conditions, giving rise to lethal castrationresistant $\mathrm{PCa}(\mathrm{CRPC})$, a highly aggressive and metastatic PCa variant. Second- and third-generation ATTs such as abiraterone (Zytiga) and enzalutamide (Xtandi) delay progression to CRPC, but are not curative. ${ }^{1}$ Standard cytotoxic chemotherapies such as docetaxel (Taxotere) and cabazitaxel (Jevtana) offer additional survival benefits of only 2-22 months before inevitable relapse, ${ }^{2,3}$ whereby greater survival benefits ( $>10-22$ months) have been reported when administered early with $A D T .{ }^{4,5}$ Nevertheless, it is clear that sequential treatment failure drives the emergence of increasingly aggressive, therapy-resistant $\mathrm{PCa}$, progressively shortening time to relapse.

Although the mechanisms underlying treatment failure and progression to CRPC are not completely understood, it is increasingly apparent that a population of tumor cells can undergo an adaptive response to ATTs. This adaptive tumor response leads to the activation of alternative tumor-promoting

\footnotetext{
${ }^{1}$ Australian Prostate Cancer Research Centre - Queensland, Institute of Health and Biomedical Innovation, School of Biomedical Science, Queensland University of Technology, Princess Alexandra Hospital, Translational Research Institute, Brisbane, Queensland, Australia; ${ }^{2}$ Vancouver Prostate Centre, University of British Columbia, Vancouver, British Columbia, Canada; ${ }^{3}$ Department of Ophthalmology and Visual Sciences, University of British Columbia, Vancouver, British Columbia, Canada; ${ }^{4}$ Tissue Repair and Regeneration Program, Institute of Health and Biomedical Innovation, Queensland University of Technology, Brisbane, Queensland, Australia; ${ }^{5}$ Dame Roma Mitchell Cancer Research Laboratories and Freemason's Foundation Centre for Men's Health, Discipline of Medicine, University of Adelaide, Adelaide, South Australia, Australia; ${ }^{6}$ GenomeDX Biosciences, Vancouver, British Columbia, Canada; ${ }^{7}$ Department of Urology, Northwestern University, Chicago, IL, USA; ${ }^{8}$ Department of Pathology and Laboratory Medicine, Mayo Clinic, Rochester, MN, USA; ${ }^{9}$ Department of Urology, Brady Urological Institute, Johns Hopkins University, Baltimore, MD, USA; ${ }^{\circ}$ Department of Urology, Mayo Clinic, Rochester, MN, USA; ${ }^{11}$ Sidney Kimmel Medical College, Thomas Jefferson University Hospital, Philadelphia, PA, USA and ${ }^{12}$ Centre for Cancer Biology, SA Pathology and University of South Australia, Adelaide, South Australia, Australia. Correspondence: Dr BG Hollier, Australian Prostate Cancer Research Centre - Queensland, Institute of Health and Biomedical Innovation, School of Biomedical Science, Queensland University of Technology, Princess Alexandra Hospital, Translational Research Institute, 37 Kent Street, Brisbane, QLD 4102 , Australia.
}

E-mail: b.hollier@qut.edu.au

${ }^{13}$ These authors contributed equally to this work.

Received 28 June 2016; revised 24 October 2016; accepted 17 November 2016; published online 16 January 2017 
pathways, alterations to androgen receptor (AR) function, and scavenging of adrenal and intra-tumoral steroids. ${ }^{6-8}$ The identification of the molecular determinants of the prostate tumor adaptation to ATTs relevant for the progression to CRPC will likely identify new candidates for therapeutic intervention. Used alongside current and emerging ATT and cytotoxic treatment combinations, these new therapies may lead to the improved clinical management of metastatic CRPC (mCRPC) and patient outcomes.

In this study, we have utilized the genome-wide transcriptional profiling of cell lines, xenografts and clinical PCa samples to identify a gene signature of tumor adaptation to ATTs. Refinement of this gene set has implicated the transmembrane glycoprotein neuropilin-1 (NRP1) in the adaptive response to ATTs and progression to CRPC. Here, we report that NRP1 is an androgensuppressed gene overexpressed in therapy-resistant tumors and mCRPC. In cell line models of $\mathrm{mCRPC}$, the short hairpin RNA (shRNA)-mediated inhibition of NRP1 expression led to a significant reduction in their invasive and metastatic capacity. Moreover, analysis of several PCa patient cohorts identified NRP1 as an independent prognostic indicator of early biochemical recurrence $(B C R)$ following radiation therapy, metastasis and $\mathrm{PCa}-$ specific mortality. This study not only provides new insights into the function of NRP1 expressed by tumor cells, but also supports the rational use of anti-NRP1 agents alongside current ATT and cytotoxic regimes in the treatment of men with advanced PCa.

\section{RESULTS}

Identification of a transcriptional signature representing the adaptive tumor response to ATTs

To characterize the adaptive response of PCa cells to ATTs, a human PCa xenograft (LNCaP) model of CRPC $^{9,10}$ was used to identify a cluster of genes significantly upregulated with castration and remaining elevated in CRPC (Figure 1a). Of these genes, a subset was repressed by the androgen dihydrotestosterone (DHT) and upregulated by enzalutamide (ENZ) in LNCaP cells in vitro (Figure 1b). Overlay of this data set with genes upregulated in human $\mathrm{MCRPC}$ versus localized $\mathrm{PCa}^{11}$ revealed a core transcriptional cluster of 120 androgen-regulated genes overexpressed in CRPC (Figure 1b, Supplementary Table 1). In an effort to identify clinically robust gene candidates, we analyzed the 120 gene set in publicly available gene expression profiling of patient metastatic versus localized $\mathrm{PCa}^{12-15}$ (Figure $1 \mathrm{c}$ ). This revealed $N R P 1$ to be significantly upregulated $(P<0.05 ; \geqslant 1.5 \mathrm{fc}$ ) in five of five data sets analyzed, with 1.9-4.7 times higher expression in metastatic samples than localized PCa samples (Figure 1d). Although studies have reported NRP1 to facilitate cancer progression in multiple tissues, $^{16-21}$ the biological role of NRP1 when expressed by PCa cells remains poorly understood. As such, we chose to characterize NRP1 expression during the adaptive response to ATTs and its role in prostate tumor progression.

NRP1 expression is suppressed by active androgen signaling In vitro validation studies confirmed NRP1 mRNA expression to be suppressed in LNCaP cells by 48 -h treatment with DHT (10 nM) or the synthetic androgen metribolone (R1881; $1 \mathrm{~nm}$ ) (Figure 2a). To determine whether the AR directly binds to the NRP1 gene loci to mediate its transcriptional repression, analysis of a chromatin immunoprecipitation (ChIP) sequencing data set $^{22}$ demonstrated AR enrichment at five putative AR-binding sites in multiple human prostate tumors (Figure $2 \mathrm{~b}$ ). We conducted ChIP assays coupled with quantitative $P C R$ using primers that amplified these five putative binding sites, detecting significant $A R$ enrichment at distal (distal_1) and intron 12 genomic regions, as well as a positive control locus (KLK3/prostate specific antigen (PSA)) in LNCaP cells cultured in the presence of androgens (Figure $2 \mathrm{c}$ ). The repressive effect of $A R$ on NRP1 expression was relieved by $A R$ knockdown using small interfering RNA (Figure 2d and Supplementary Figure 1) or treatment with the AR inhibitors bicalutamide (Bic) and Enz (Figure 2e). In concordance, NRP1 mRNA (Figure $2 \mathrm{f}$ ) and protein (Figure $2 \mathrm{~g}$ ) levels rose in response to in vitro androgen deprivation with $5 \%$ charcoal-stripped serum (CSS) supplementation over 7 days. Notably, the re-introduction of DHT attenuated the CSS-mediated increase in NRP1 mRNA and protein levels (Figures $2 f$ and $g$ ), however, NRP1 levels remained elevated compared with basal levels in androgen containing media (fetal bovine serum (FBS)). Consistent with this in vitro data, surgical castration of mice significantly elevated NRP1 mRNA levels in LuCAP35 tumor xenografts as compared with sham-castrated controls (Figure 2h). Taken together, these data indicate that active AR signaling may directly mediate the suppression of NRP1 expression. a

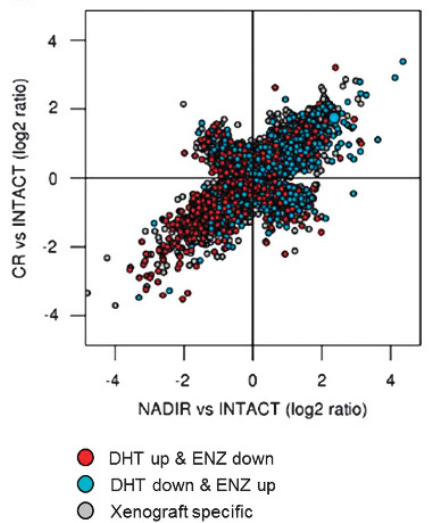

b

LNCaP In vitro LNCaP Xenograft

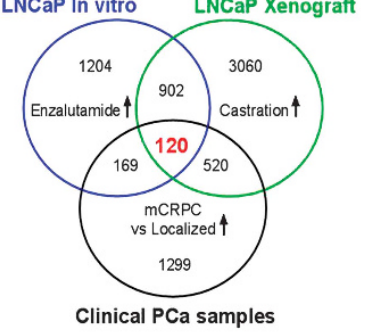

C

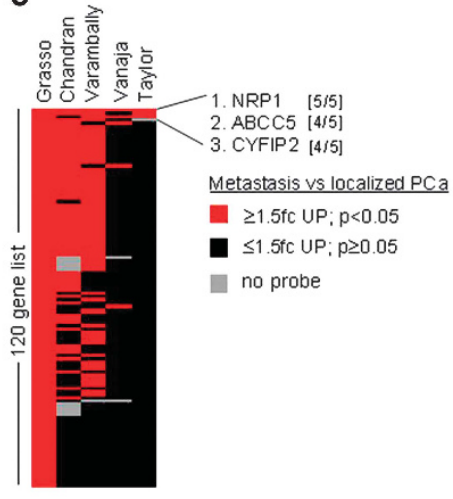

d

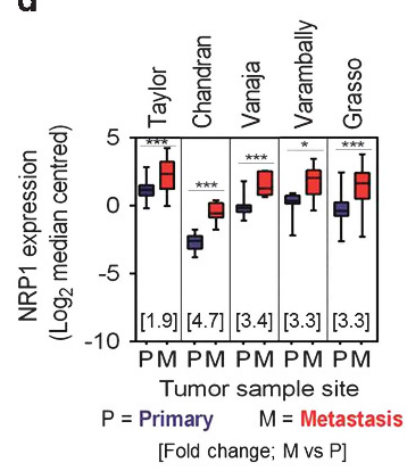

Figure 1. Transcriptional signature of the adaptive tumor response to ATTs. (a) Genes differentially expressed following castration of host mice versus non-castrated ('intact') LNCaP tumor xenografts at PSA nadir and CR. NRP1 is indicated by the large blue dot in the upper right quadrant. (b) Numbers of genes common to three data sets: LNCaP Enz-upregulated genes (top left), genes upregulated in LNCaP xenografts post-castration (top right) and genes upregulated in MCRPC versus localized PCa (Grasso et al., bottom; ${ }^{11}$ GSE35988). (c) Heatmap showing differential expression of the 120 gene subset identified in $\mathbf{b}$ in metastatic versus localized PCa data sets. ${ }^{11-15}$ (d) NRP1 mRNA levels in clinical samples of metastasis versus primary localized PCa across multiple data sets. ${ }^{11-15} * P<0.05, * * * P<0.001$. In $\mathbf{c}$ and $\mathbf{d}$, $\log _{2}$ median centered gene expression data was downloaded from the Oncomine database. 


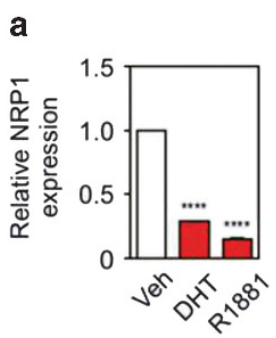

Chr10: $33.45033 .50033 .55033 .60033 .65033 .700 \mathrm{~kb}$
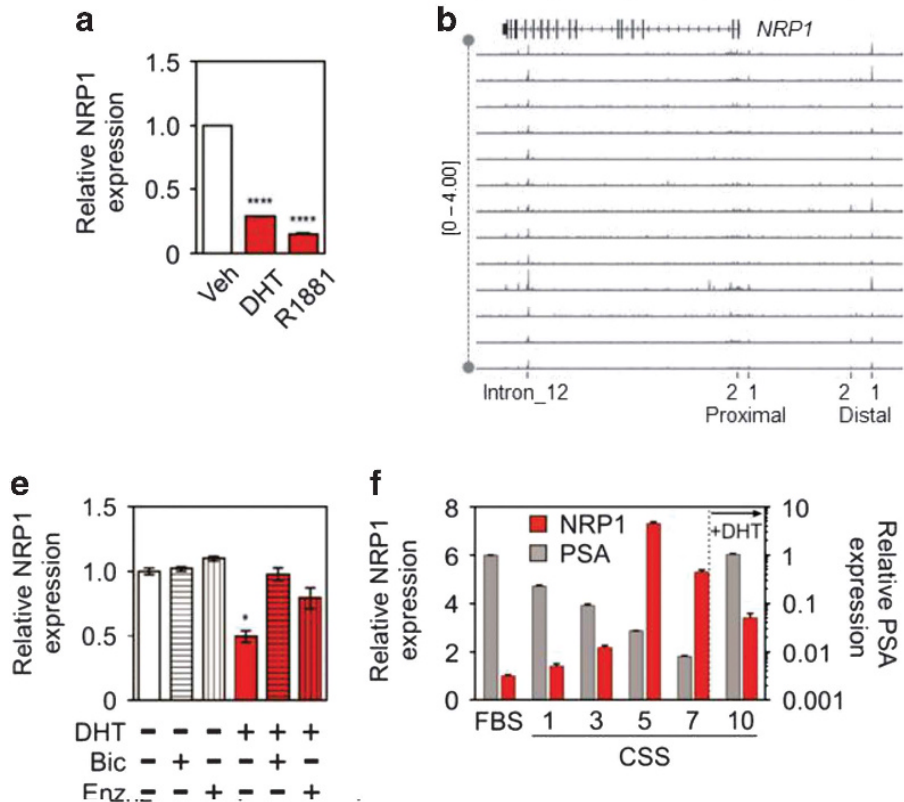

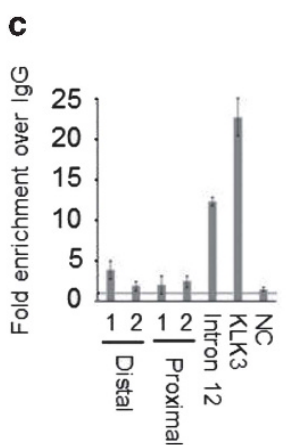

d
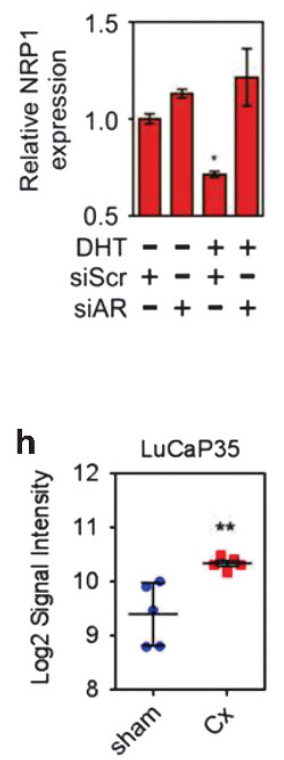

Figure 2. Regulation of NRP1 expression by the androgen signaling axis. (a) Relative NRP1 mRNA expression in LNCaP cells grown in CSS after 48-h treatment with $10 \mathrm{~nm} \mathrm{DHT,} 1 \mathrm{~nm}$ R1881 or vehicle. (b) Modified UCSC screenshot showing AR binding sites (ChIP-seq) proximal to the NRP1 gene in 13 PCa samples ${ }^{22}$ (GSE70079). Each track depicts ChIP-seq AR binding intensity for a given sample. (c) ChIP-quantitative PCR ( $\mathrm{PPCR}$ ) demonstrates AR binding to distal 1 and Intron_12 regions at the NRP1 gene locus. The dotted line demarcates no enrichment over an IgG control ChIP. A known AR binding site in the KLK3 enhancer region was used as a positive control, whereas a gene-poor region on chromosome 20 with no previous evidence of AR binding was used as a negative control (NC). (d) NRP1 expression in LNCaP cells grown in CSS after 48- $\mathrm{h}$ treatment with $10 \mathrm{~nm}$ DHT and AR or scrambled control (scr) small interfering RNA. For AR and KLK3/PSA mRNA levels refer to Supplementary Figure 1. (e) NRP1 expression in LNCaP cells grown in CSS after 48- $\mathrm{h}$ treatment with $10 \mathrm{~nm}$ DHT with or without Bic or ENZ cotreatment. (f) qPCR analysis of NRP1 and PSA expression and $(\mathbf{g})$ western blot analysis of NRP1 expression in LNCaP cells after culture in CSS for 1, 3, 5 or 7 days, or 7 days followed by 3 days of DHT treatment (10 nM). (h) NRP1 mRNA expression levels in LuCaP35 xenografts following sham castration (sham) or castration (Cx) of host mice. Raw expression data from GSE33316. ${ }^{51} P<0.05$; ${ }^{* *} P<0.01$; ${ }^{* * * *} P<0.0001$.

NRP1 is upregulated during the adaptive response to ATTs and progression to CRPC

We have previously established the LNCaP xenograft model to mimic the in vivo progression to CRPC following castration. ${ }^{9,10}$ The transcriptional profiling of LNCaP tumors following castration of host mice identified NRP1 levels to peak at post-castration PSA nadir and remain elevated with progression to castration resistance (CR; Figure 3a). Increased NRP1 protein expression was also observed in an androgen-independent LNCaP variant cell line generated following long-term culture in androgendeprived conditions (LNCaP-Al), ${ }^{23}$ compared with their androgendependent parental cells (Figure 3b). Next, we assessed the expression levels of NRP1 in clinical samples of CRPC. Analysis of gene expression data obtained from laser capture microdissected samples from treatment naive or hormone refractory primary tumor samples ${ }^{24}$ identified significantly higher NRP1 mRNA expression in men with hormone refractory progressive disease (PD; Figure 3c). This was confirmed by transcriptional profiling of mCRPC samples by Grasso et al., ${ }^{11}$ which showed a significant upregulation of NRP1 expression in heavily pre-treated samples of mCRPC compared with either localized PCa or benign tissue samples (Figure $3 d$ ). No significant difference in expression was observed between benign and localized PCa samples (Figure 3d). Moreover, RNA-sequencing data of 150 mCRPC bone or soft tumor biopsies ${ }^{25}$ identified the substantial expression of NRP1 in these tumors to be further increased in patients treated with abiraterone (Abi) or Enz versus neither treatment (Figure 3e). Collectively, these data establish NRP1 to be dynamically regulated during the prostate tumor adaptation to ATTs and progression to mCRPC.
NRP1 is required for the invasion and metastatic dissemination of mCRPC cell models

As few reports have described a functional role for NRP1 when expressed directly by PCa cells, we next investigated the effect of NRP1 on the invasive and metastatic phenotype. Flow cytometric profiling revealed cell surface NRP1 levels to be relatively low in the benign prostate epithelial cell lines BPH-1 and RWPE-1, but elevated in tumor cells with increasing invasive and metastatic potential, with highest expression seen in the castration-resistant and metastatic PC3 line (Figure 4a). To determine the effect of NRP1 suppression on the phenotype of PCa cells, two stable NRP1

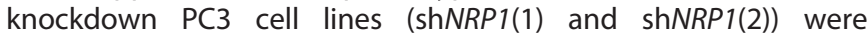
generated using the pLKO.1 lentiviral vector (Figure 4b). No significant difference in proliferation was observed between NRP1 knockdown and control cell lines as measured by either cell confluence or DNA content quantification (Figure 4c). However, we observed that NRP1 knockdown caused PC3 cells to grow as more compact and non-invasive colonies over a 10-day period in both monolayer (Figure 4d) and modified three-dimensional (3D) On-top Matrigel cultures (Figure 4e). A reduction in invasive capacity following NRP1 suppression in PC3 cells, as well as the additional metastatic and castrate resistant DU145 cell line, was confirmed using wound scratch invasion studies (Supplementary Figure 2).

As previous reports have implicated NRP1 in the epithelialmesenchymal transition phenotype, ${ }^{26,27}$ a developmental program capable of endowing tumor cells with invasive properties, ${ }^{28}$ we next assessed the mesenchymal properties of PC3 cells upon NRP1 knockdown. The expression of the prototypical mesenchymal and epithelial markers, vimentin and E-cadherin, respectively, 
a

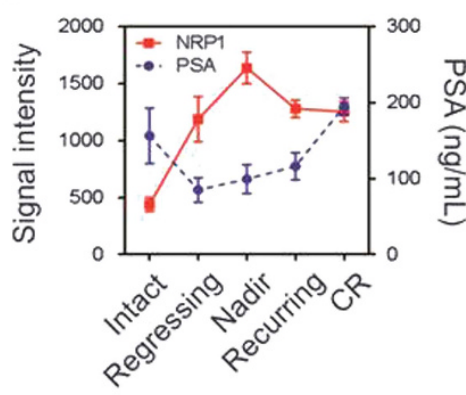

b

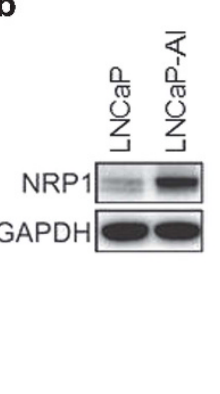

C

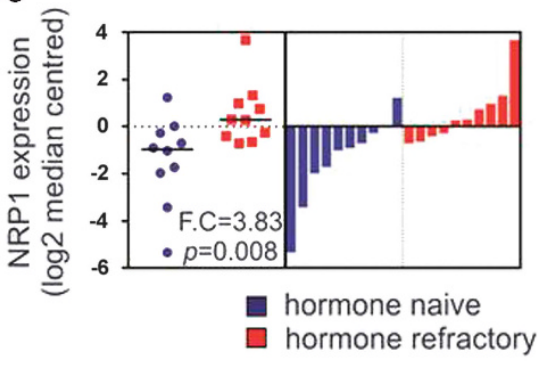

d

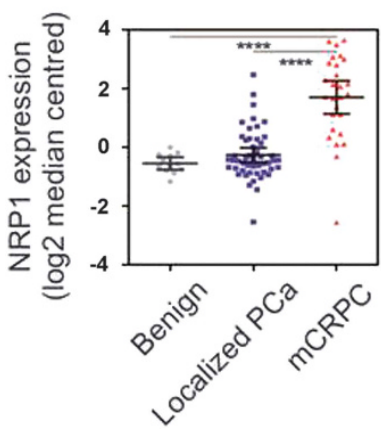

e SU2C/PCF Dream Team

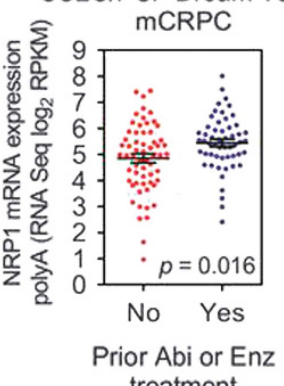

treatment

Figure 3. NRP1 expression is dynamically regulated during the adaptive response to ATTs and progression to mCRPC. (a) Microarray analysis of NRP1 expression in LNCaP xenografts harvested from non-castrated mice (intact) and during progression to CR after castration of host nude mice. (b) Western blot of NRP1 in parental LNCaP cells and their androgen-independent variant, LNCaP-Al. (c) NRP1 mRNA expression in hormone naive primary PCa biopsies compared with hormone refractory samples from data set GDS1390. ${ }^{24}$ (d) NRP1 mRNA levels in benign, localized PCa and MCRPC samples from Grasso et al. ${ }^{11}$ Data extracted from GSE35988. (e) Scatterplot showing log 2 RPKM normalized NRP1 RNA-seq read counts from individual mCRPC samples $(n=118)$ from the Stand Up To Cancer (SU2C)/Prostate Cancer Foundation (PCF) Dream Team cohort. ${ }^{25}$ Data obtained from cBioPortal. ${ }^{52,53}$ (d, e) Error bars represent s.e.m. ${ }^{* * * *} P<0.0001$.

were examined using the In-Cell Western technique LI-COR Biosciences (Lincoln, NE, USA) on monolayer cultures (Figure $4 \mathrm{f}$ ) or immunofluorescence staining of cells grown in 3D On-top Matrigel cultures (Figure $4 \mathrm{~g}$ ). In both monolayer and 3D cultures, the suppression of NRP1 levels resulted in reduced vimentin and increased E-cadherin protein expression (Figures $4 \mathrm{f}$ and $\mathrm{g}$ ). The reduction in NRP1 expression was also associated with increased cortical actin staining (Figure $4 \mathrm{~g}$ ), a characteristic of epithelial cell types. Next, we assessed the impact of NRP1 knockdown on metastatic dissemination. Control (shCntrol) and NRP1 knockdown PC3 cells were xenografted into the yolk sacs of dechorionated 2-day post-fertilization wild-type zebrafish embryos and metastasis, measured as cell dissemination outside the yolk sac, was imaged 5 days later. In comparison with control cells, which disseminated toward the head and tail of the fish, a significantly reduced proportion of zebrafish were positive for metastasis following injection of the NRP1 knockdown cell lines (Figures $4 \mathrm{~h}$ and i). Collectively, these data provide evidence that NRP1 is required for the invasion and metastatic dissemination of $\mathrm{MCRPC}$ cell models, which may be mediated via its regulation of the mesenchymal phenotype.

Increased NRP1 expression is associated with primary tumor progression and therapy failure

Previous studies have reported a positive association between NRP1 expression and Gleason grade in immunohistochemical (IHC) analyses of small patient cohorts (5-17 specimens per Gleason grade). ${ }^{16,18}$ We expanded upon these studies by performing IHC staining for NRP1 using a Gleason grade tissue microarray containing 176 patient specimens (cohort summarized in Supplementary Table 2). Results from this larger cohort supported previous observations, with strong NRP1 staining more frequently observed in higher Gleason grade tumors (Figure 5a). In addition, analysis of RNA-sequencing data from The Cancer Genome Atlas (TCGA) Prostate Adenocarcinoma (PRAD) cohort (http://xena.ucsc.edu) revealed increased NRP1 mRNA expression to be associated with increasing pathological stage and node status in a large cohort $(n=498)$ of primary tumor samples (Figure 5b). RNA sequencing of the TCGA PRAD cohort also identified significantly elevated NRP1 expression in tumor samples from men with progressive disease (PD) following primary therapy versus those who had complete response (CR; Figure 5b). KaplanMeier analysis of the TCGA PRAD cohort showed significantly lower probability of relapse-free survival in men with higher than median NRP1 expression (Figure 5c).

NRP1 predicts biochemical failure in patients after postoperative radiation therapy

As TCGA analysis revealed elevated NRP1 expression in the primary tumors of patients who failed primary therapy, we next investigated the significance of NRP1 as a predictive biomarker for BCR after primary therapies. NRP1 expression at RP was analyzed with reference to patient outcome in a cohort of 130 patients who underwent post-RP adjuvant or salvage radiotherapy at the Kimmel Cancer Center, Thomas Jefferson University (TJU), Philadelphia, PA, USA ${ }^{29}$ (Figure $5 \mathrm{~d}$ ). All patients were diagnosed with pT3 or margin positive disease at the time of radiotherapy. Significantly higher NRP1 expression was observed in patients who developed post-radiotherapy BCR compared with patients who did not (Figures 5e and f). This was confirmed by KaplanMeier survival analysis revealing patients with high NRP1 expression to have a rapid progression to $B C R$, suggestive of a 
a

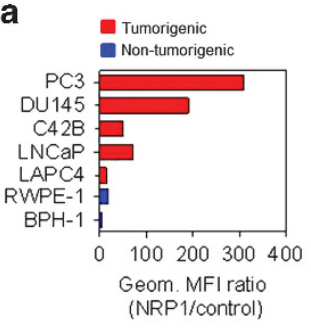

b

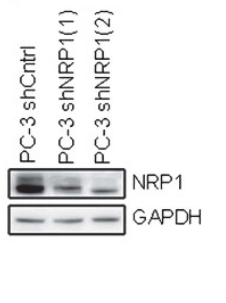

d

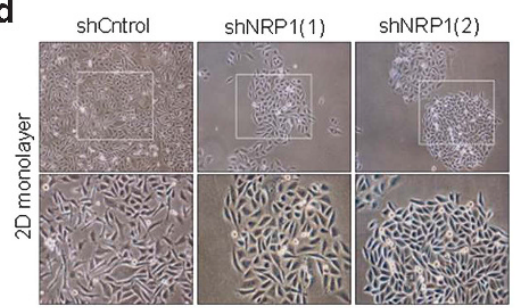

C
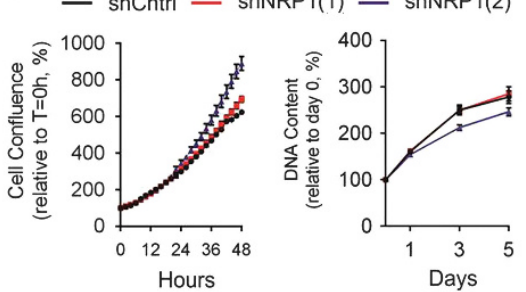

e

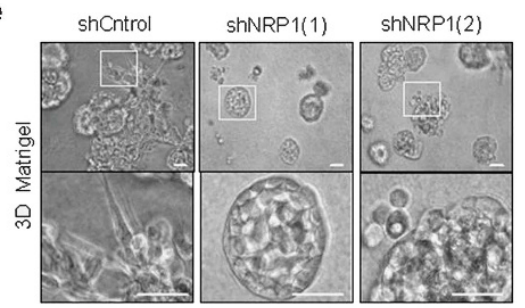

h

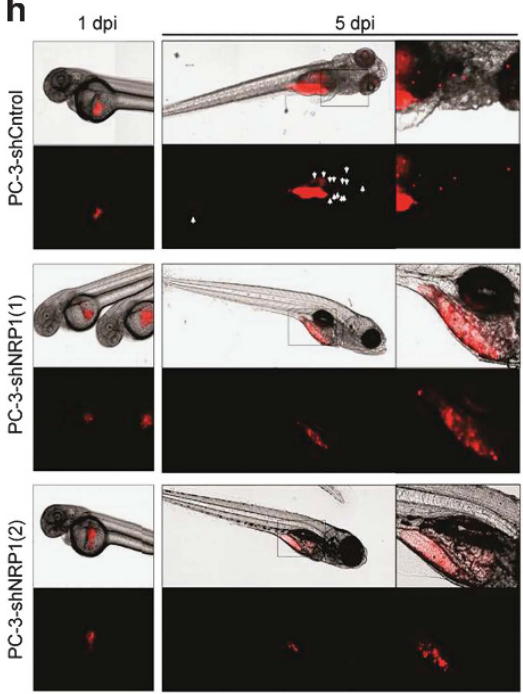

f

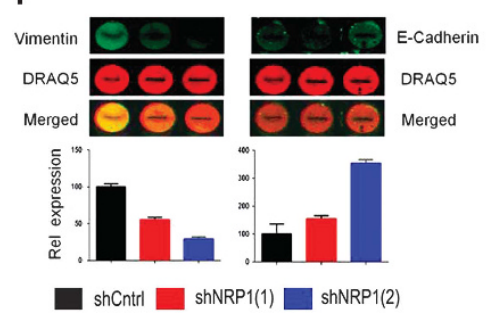

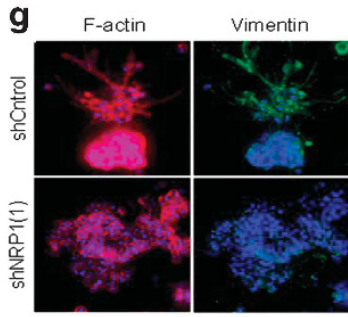
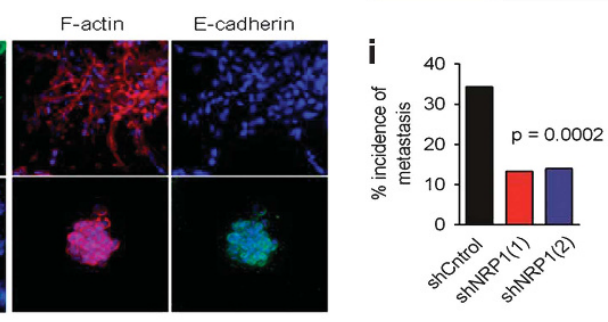

Figure 4. NRP1 promotes the invasion and metastatic dissemination of $m C R P C$ cell models. (a) Flow cytometric quantification of NRP1 protein levels in benign (BPH-1, RWPE-1) and tumorigenic PCa cell lines. Error bars: s.d. $n=3,{ }^{*} P<0.05$. (b) Western blot of NRP1 expression in PC3shCntrl, -shNRP1(1) and -shNRP1(2) total cell lysates. (c) Left panel: relative confluence of PC3-shCntrl (black lines), -shNRP1(1) (red lines) and -shNRP1(2) (blue lines) cells over $48 \mathrm{~h}$ measured by the CellPlayer Kinetic Proliferation assay. Right panel: DNA content in the same cell lines quantified by PicoGreen assay after 1, 3 and 5 days. (d) Representative phase-contrast images of PC3-shRNA models grown in 2D monolayer and (e) 3D On-top Matrigel cultures. Scale bars, $100 \mu \mathrm{m}$. (f) Quantification of vimentin and E-cadherin protein expression using the In-Cell Western technique (LI-COR) on intact PC3-shCntrl, -shNRP1(3) and -shNRP1(5) cells. Wells were stained immediately following wound scratch assays reported in Supplementary Figure 2. Bar chart displays combined intensity data ( $n=16$ wells from three experiments). Error bars: s.d. (g) Vimentin and E-cadherin protein expression detected by immunofluorescence in PC3-shCntrl and -shNRP1(3) cells after 10 days of 3D Ontop Matrigel culture. Red: actin; blue: DAPI. $\times 60$ magnification. (h) Zebrafish-xenografted control (shCntrol) and NRP1 knockdown (shNRP1 (1) and shNRP1 (2)) PC3 cells (red fluorescent signal) at 1 day (left panels) and 5 days (right panels) post-injection (dpi). White arrows indicate metastatic dissemination outside of the yolk sac. (i) Percentage incidence of metastasis in xenografted zebrafish ( $n=64$, shContrl; $n=30$, $\operatorname{shNRP1}(1) ; n=28, \operatorname{sh} N R P 1$ (2)). $P=0.0002$ (chi-square test).

greater presence or outgrowth of occult metastases (Figure $5 \mathrm{~g}$ ). Finally, multivariate analysis identified high NRP1 expression as a significant independent predictor of $\mathrm{BCR}(P=0.019$, Supplementary Table 3). Taken together, these data provide novel insight into the expression of NRP1 in clinical samples of primary $\mathrm{PCa}$ and its positive association with aggressive clinicopathological parameters.

NRP1 is an independent prognostic biomarker of metastatic progression and cancer-specific mortality

As a small minority of patients from the TJU cohort developed distal metastases during follow-up, we analyzed the ability of NRP1 to predict metastasis in a larger cohort. Hence, NRP1 expression at RP was analyzed for its ability to predict metastasis, defined by positive bone or computed tomography scan, in a cohort of 545 patients who had undergone RP at the Mayo Clinic ${ }^{30}$ (Figure 6a). NRP1 expression was found to be significantly higher in patients who were positive for metastasis (Figures $6 \mathrm{~b}-\mathrm{c}$ ) and prostate cancer-specific mortality (PCSM; Figures $6 \mathrm{~d}$ and e). Moreover, multivariate analysis identified high NRP1 expression at RP as a significant independent predictor of both metastatic progression $(P=0.008)$ and PCSM $(P=0.013$; Table 1$)$.
To further validate these findings, we performed a similar analysis in a Natural History cohort of 644 intermediate- and highrisk men who underwent RP at Johns Hopkins Medical Institutions (JHMI). ${ }^{31}$ In this unique cohort, patients received no adjuvant or salvage therapy following RP until metastatic progression. Again, high NRP1 expression was associated with lower probability of metastasis-free survival (Figure 7a) and was an independent predictor of metastatic progression $(P=0.048$, Table 1$)$. Within a subgroup of 211 patients who were positive for BCR (Figure 7b), NRP1 was associated with a shorter time to PCSM (Figure 7b) and was a significant predictor of PCSM ( $P=0.034$; Table 1). Overall, these results define NRP1 as a novel biomarker for identifying patients at risk of metastatic progression and death from PCa after RP.

\section{DISCUSSION}

Despite the introduction of new androgen-targeting agents ENZ and Abi acetate into treatment regimens for CRPC, it remains incurable. ${ }^{1,6}$ Androgens are potent growth and differentiation factors for prostate tissue, and loss of this differentiation pressure is an unintended consequence of ATTs. This can result in the initiation of de-differentiation and trans-differentiation cell 

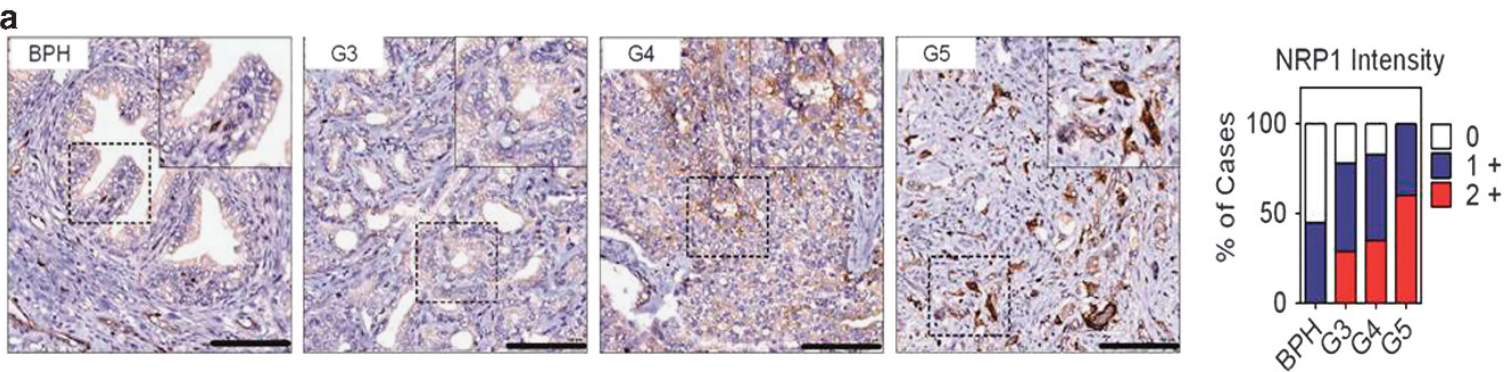

b

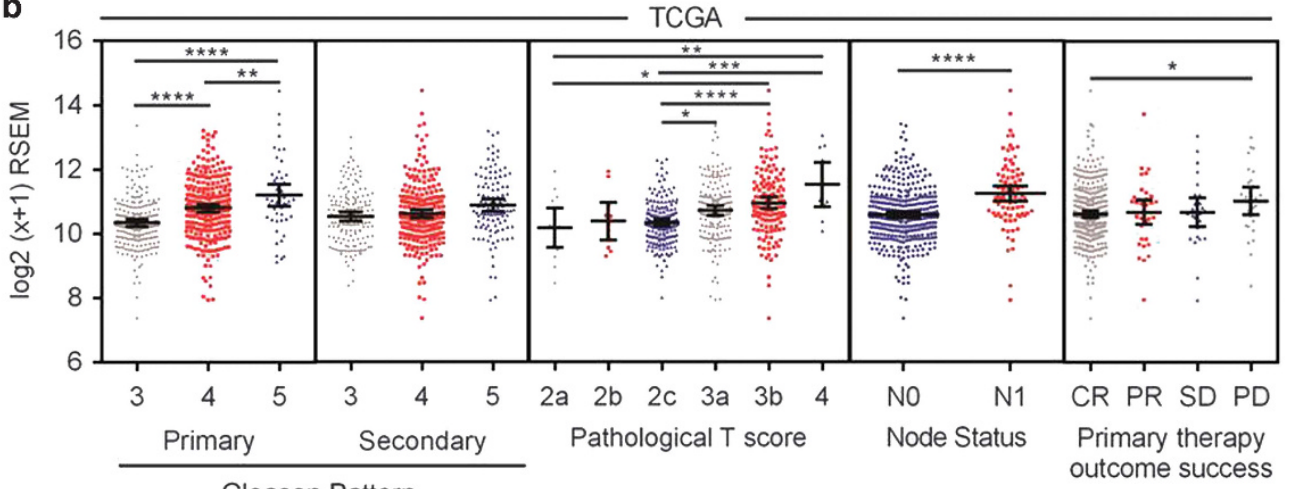

Gleason Pattern

C

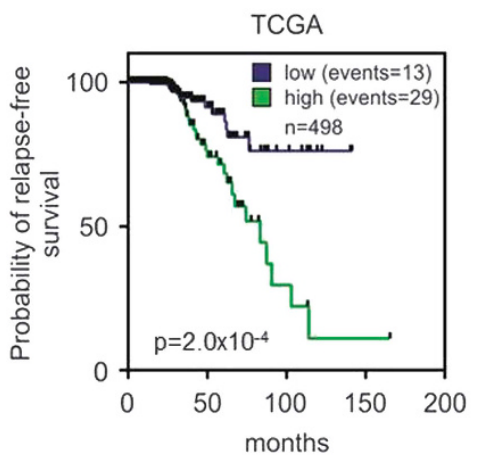

e

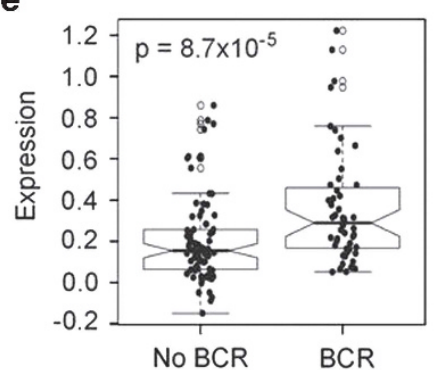

d

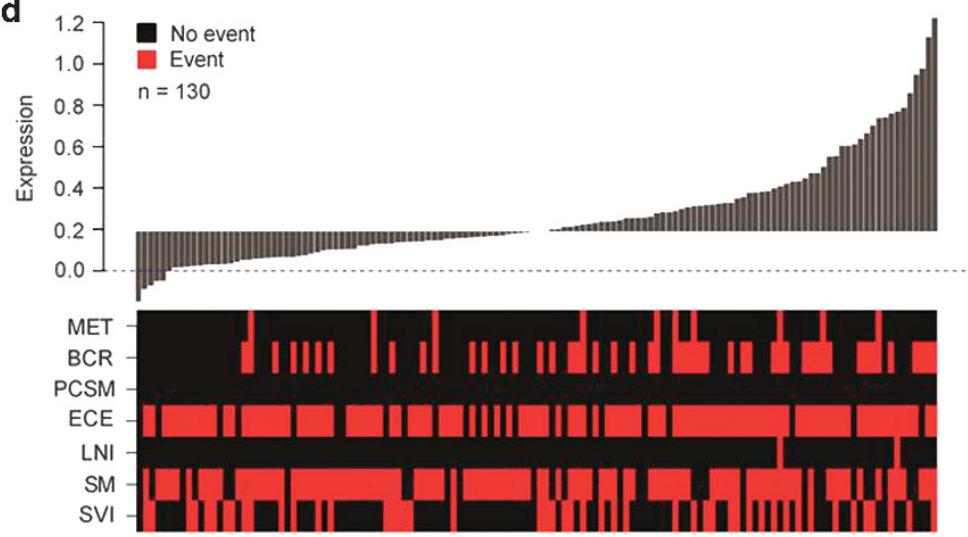

f

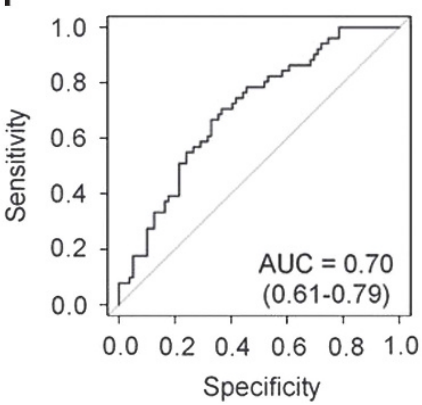

Figure 5. Increased NRP1 expression is associated with tumor progression and primary therapy failure. (a) Representative images of BPH and Gleason grade 3,4 or $5(G 3, G 4, G 5)$ tumor samples from a tissue microarray stained for NRP1. Scale bars, $100 \mu \mathrm{m}$. Right panel: summary of NRP1 staining intensity scores across Gleason grades. Scoring scale: no staining (0), low $(+1)$, moderate to high (+2). (b) RNA-sequencing data from the TCGA PRAD cohort comparing NRP1 mRNA expression in patients with tumors of varying Gleason pattern (primary and secondary, leftmost 2 panels), pathological T scores (middle panel) and node status/response to primary therapy (rightmost 2 panels). ${ }^{*} P<0.05$; ${ }^{* *} P<0.01$; ${ }^{* *} P<0.001$; ${ }^{* * *} P<0.0001$. PR, partial response; SD, stable disease. (c) Kaplan-Meier curves showing relapse-free survival in 498 PCa patients stratified according to the median levels (high versus low) for NRP1 expression (RNA-seq, log2 $(x+1)$ RSEM) in the TCGA PRAD cohort. (d) NRP1 expression in TJU post-radiotherapy samples. Each sample is annotated in the colored matrix below the plot. ECE, extracapsular extension; LNI, lymph node invasion; MET, metastasis; SM, surgical margin; SVI, seminal vesicle invasion. (e) Boxplot showing NRP1 expression in patients positive and negative for BCR. (f) ROC curve for NRP1 expression predicting BCR. (g) Kaplan-Meier curve showing BCRfree survival for NRP1 high and low expression groups. 

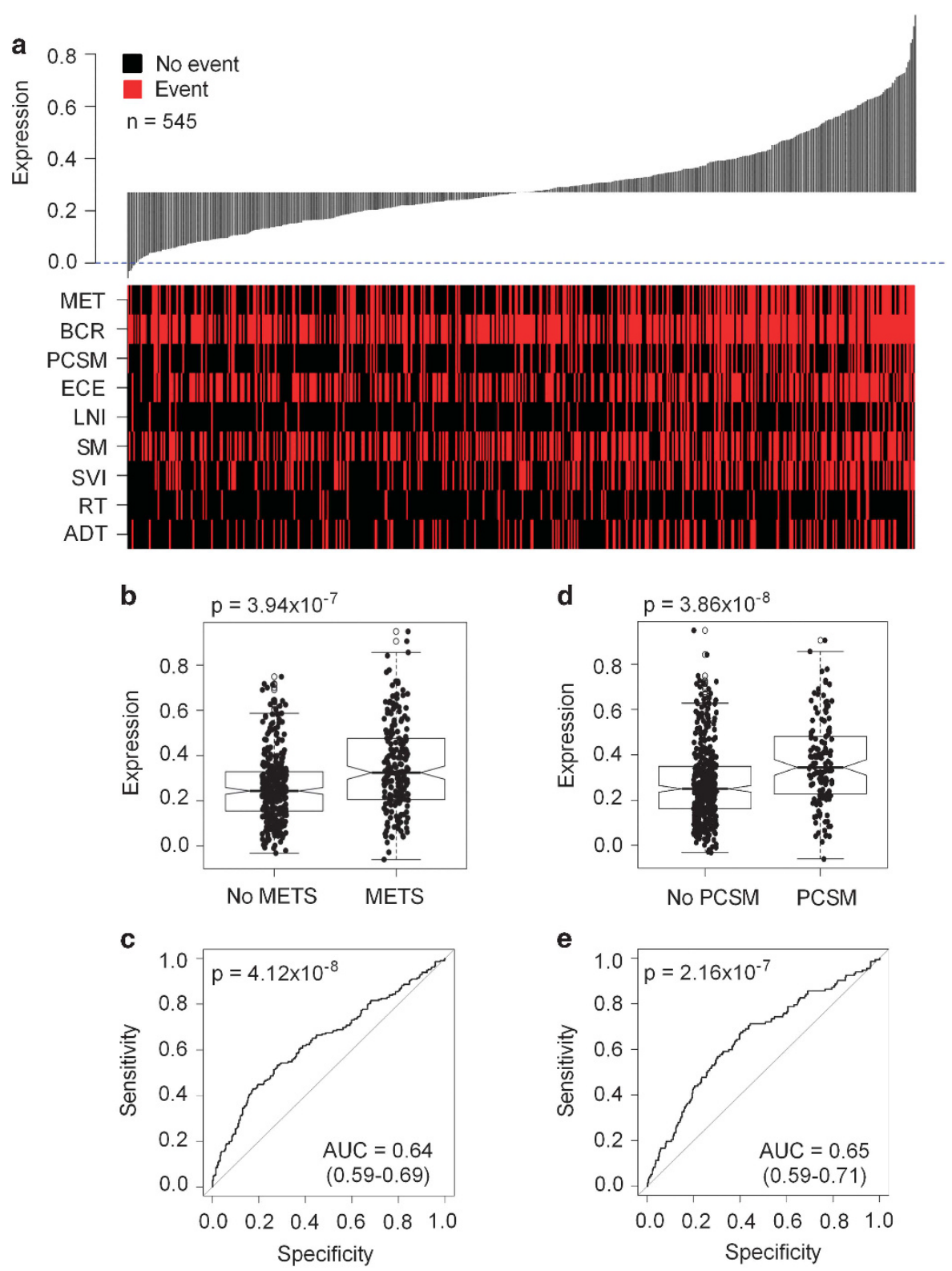

Figure 6. NRP1 expression predicts metastasis and PCSM following RP. (a) NRP1 expression in Mayo Clinic patient samples. Each sample is annotated in the colored matrix below the plot. ADT, androgen deprivation therapy; ECE, extra-capsular extension; LNI, lymph node invasion; MET, metastasis; RT, radiation therapy; SM, surgical margin; SVI, seminal vesicle invasion. (b) NRP1 expression in patients positive and negative for METS. (c) ROC curve for NRP1 expression predicting metastasis. (d) NRP1 expression in patients positive and negative for PCSM. (e) ROC curve for NRP1 expression predicting PCSM.

plasticity programs, which enable survival under low androgen conditions. $^{32}$ Hence, identifying biomarkers and molecular determinants of the adaptive progression to metastatic castrateresistant disease is critical for the development of more effective treatments. Here, we identify NRP1 as one of a subset of androgen-suppressed genes persistently overexpressed in CRPC in both an in vivo human xenograft model of CRPC and clinical $\mathrm{mCRPC}$.

Although ATTs initially suppress androgen signaling, this pathway is re-activated in $\mathrm{CRPC}^{8,33} \mathrm{~A}$ possible explanation of the sustained NRP1 overexpression in CRPC despite re-activated androgen signaling may involve the transcriptional activity of CRPC-associated AR splice variants. ${ }^{34} \mathrm{~A}$ recent report identified NRP1 to be upregulated by AR variants expressed in 22Rv1 cells, but not full-length AR, in the absence of androgens. ${ }^{35}$ In addition, NRP1 formed part of a 297 gene signature capable of distinguishing localized PCa from CRPC, and was 1 of 34 probes significantly associated with shorter time to post-RP BCR. ${ }^{35}$ In concordance, we report NRP1 to be associated with shorter time to relapse following primary therapy in the TCGA PRAD cohort and an independent predictor of PCa recurrence following post-RP radiation therapy in a 130-patient cohort from the TJU.

We report for the first time that high NRP1 expression in primary tumors at the time of RP is an independent predictor of clinical metastasis and cancer-specific mortality in two clinical cohorts from the Mayo Clinic and JHMI. Further studies will be required to decipher whether NRP1 is solely a biomarker for identifying patients at risk of metastatic progression and death from PCa or 
Table 1. Multivariable Cox proportional hazards analysis of risk factors for postoperative RT biochemical failure, clinical metastasis and prostate cancer-specific mortality

\begin{tabular}{|c|c|c|c|}
\hline \multicolumn{4}{|c|}{ Post-radiotherapy $B C R$} \\
\hline & \multicolumn{3}{|c|}{ TJU } \\
\hline & $H R$ & $95 \% \mathrm{Cl}$ & P-value \\
\hline NRP1 & 2.30 & $1.14-4.62$ & 0.019 \\
\hline $\mathrm{GS}<8$ & 0.53 & $0.12-2.40$ & 0.410 \\
\hline $\mathrm{GS} \geq 8$ & 2.85 & $1.46-5.57$ & 0.002 \\
\hline Lymph node involvement & 1.55 & $0.20-12.27$ & 0.676 \\
\hline Positive surgical margin & 0.95 & $0.45-2.00$ & 0.897 \\
\hline Extra-capsular extension & 1.67 & $0.62-4.54$ & 0.311 \\
\hline Seminal vesicle invasion & 1.38 & $0.71-2.67$ & 0.344 \\
\hline Pre-operative PSA $10-20 \mathrm{ng} / \mathrm{ml}$ & 1.59 & $0.69-3.66$ & 0.275 \\
\hline Pre-operative PSA > $20 \mathrm{ng} / \mathrm{ml}$ & 1.64 & $0.69-3.92$ & 0.261 \\
\hline \multicolumn{4}{|c|}{ Metastasis } \\
\hline & \multicolumn{3}{|c|}{ Mayo Clinic } \\
\hline & $H R$ & $95 \% \mathrm{Cl}$ & P-value \\
\hline NRP1 & 1.73 & $1.15-2.59$ & 0.008 \\
\hline $\mathrm{GS}<8$ & 0.36 & $0.13-0.82$ & 0.026 \\
\hline$G S \geqslant 8$ & 3.49 & $2.31-5.30$ & $<0.0001$ \\
\hline Lymph node involvement & 1.50 & $0.82-2.76$ & 0.194 \\
\hline Positive surgical margin & 0.93 & $0.61-1.39$ & 0.714 \\
\hline Extra-capsular extension & 1.31 & $0.86-1.99$ & 0.210 \\
\hline Seminal vesicle invasion & 1.57 & $0.98-2.50$ & 0.060 \\
\hline Pre-operative PSA $10-20 \mathrm{ng} / \mathrm{ml}$ & 0.73 & $0.44-1.22$ & 0.237 \\
\hline \multirow[t]{3}{*}{ Pre-operative PSA $>20 \mathrm{ng} / \mathrm{ml}$} & 0.80 & $0.47-1.34$ & 0.392 \\
\hline & \multicolumn{3}{|c|}{$J H M I$ post-RP } \\
\hline & $H R$ & $95 \% \mathrm{Cl}$ & P-value \\
\hline NRP1 & 1.91 & $1.01-3.61$ & 0.048 \\
\hline $\mathrm{GS}<8$ & NA & NA & NA \\
\hline $\mathrm{GS} \geqslant 8$ & 4.26 & $2.25-8.08$ & $<0.0001$ \\
\hline Lymph node involvement & 3.05 & $1.49-6.25$ & 0.002 \\
\hline Positive surgical margin & 1.05 & $0.53-2.09$ & 0.894 \\
\hline Extra-capsular extension & 2.28 & $1.01-5.15$ & 0.048 \\
\hline Seminal vesicle invasion & 2.40 & $1.20-4.78$ & 0.013 \\
\hline Pre-operative PSA $10-20 \mathrm{ng} / \mathrm{ml}$ & 1.87 & $0.93-3.76$ & 0.081 \\
\hline Pre-operative PSA $>20 \mathrm{ng} / \mathrm{ml}$ & 1.11 & $0.41-3.01$ & 0.840 \\
\hline
\end{tabular}

\begin{tabular}{|c|c|c|c|}
\hline & \multicolumn{3}{|c|}{ Mayo Clinic } \\
\hline & $H R$ & $95 \% \mathrm{Cl}$ & P-value \\
\hline NRP1 & 1.83 & $1.14-2.98$ & 0.013 \\
\hline $\mathrm{GS}<8$ & 0.71 & $0.20-1.94$ & 0.540 \\
\hline$G S \geqslant 8$ & 3.52 & $2.18-5.75$ & $<0.0001$ \\
\hline Lymph node involvement & 2.33 & $1.26-4.32$ & 0.007 \\
\hline Positive surgical margin & 1.42 & $0.89-2.29$ & 0.141 \\
\hline Extra-capsular extension & 1.46 & $0.89-2.39$ & 0.131 \\
\hline Seminal vesicle invasion & 2.14 & $1.28-3.59$ & $<0.0001$ \\
\hline Pre-operative PSA $10-20 \mathrm{ng} / \mathrm{ml}$ & 0.82 & $0.45-1.46$ & 0.500 \\
\hline \multirow[t]{3}{*}{ Pre-operative PSA > $20 \mathrm{ng} / \mathrm{ml}$} & 0.61 & $0.33-1.10$ & 0.105 \\
\hline & \multicolumn{3}{|c|}{$J H M I$ post $-B C R$} \\
\hline & $H R$ & $95 \% \mathrm{Cl}$ & P-value \\
\hline NRP1 & 2.01 & $1.05-3.85$ & 0.034 \\
\hline $\mathrm{GS}<8$ & NA & NA & NA \\
\hline $\mathrm{GS} \geqslant 8$ & 4.53 & $2.28-9.01$ & $<0.0001$ \\
\hline Lymph node involvement & 0.97 & $0.45-2.08$ & 0.930 \\
\hline Positive surgical margin & 0.54 & $0.26-1.11$ & 0.094 \\
\hline Extra-capsular extension & 0.77 & $0.32-1.83$ & 0.552 \\
\hline Seminal vesicle invasion & 2.74 & $1.25-5.98$ & 0.012 \\
\hline Pre-operative PSA $10-20 \mathrm{ng} / \mathrm{ml}$ & 1.04 & $0.50-2.16$ & 0.925 \\
\hline Pre-operative PSA $>20 \mathrm{ng} / \mathrm{ml}$ & 1.03 & $0.37-2.90$ & 0.955 \\
\hline
\end{tabular}

Abbreviations: $\mathrm{BCR}$, biochemical recurrence; $\mathrm{Cl}$, confidence interval; $\mathrm{GS}$, Gleason score; HR, hazard ratio; JHMI, Johns Hopkins Medical Institutions; NA, not applicable; NRP1, neuropilin-1; PSA, prostate specific antigen; RT, radiation therapy; TJU, Thomas Jefferson University. Bold values indicate $P<0.05$. actively contributes to metastatic and therapy-resistant disease. We demonstrate NRP1 is required for the full metastatic potential of tumor cells using an in vivo Zebrafish model. Although studies using xeno-transplantation into mice and transgenic models will be necessary for validation, the Zebrafish model is becoming increasingly recognized as a rapid, robust and inexpensive assay that can faithfully recapitulate the metastatic potential of numerous human cancer cell models. ${ }^{36}$ Given the relatively short duration of studies (normally $<1$ week) that can be performed using the Zebrafish model, mouse studies will be critical for deciphering the role of NRP1 in the formation of occult metastases and their outgrowth over more extended periods.

Collectively, the data reported herein support the rational therapeutic targeting of NRP1 to inhibit prostate tumor progression. A recent Genentech-led Phase $1 \mathrm{~b}$ clinical trial failed to demonstrate efficacy of the NRP1 antibody MNRP1685A (Vesencumab), targeted against the vascular endothelial growth factor (VEGF)-binding site of NRP1, as a mono drug therapy in a mixed cancer patient cohort, which did not include PCa patients. ${ }^{37}$ In combination with the VEGF inhibitor bevacizumab, MNRP1685A administration led to a high incidence of proteinuria, prompting withdrawal of the drug. As we report for the first time that NRP1 is expressed in a dynamic manner during the adaptive response of tumors to ATTs, NRP1-targeted compounds may prove more efficacious in a PCa context when administered as adjuvant therapies alongside agents targeting the androgen signaling axis. In the absence of additional VEGF inhibitors, renal side effects may be expected to be less pronounced.

Ligands outside the VEGF family, such as transforming growth factor- $\beta{ }^{38}$ platelet-derived growth factor- $\mathrm{BB},{ }^{39}$ fibroblast growth factors- $1,-2$ and -4 and hepatocyte growth factor, ${ }^{40}$ also have a role in mediating the biological effects of NRP1. As such, agents aimed at more broadly inhibiting NRP1 activity, rather than specific blockade of the VEGF-binding site, may prove a more effective strategy in targeting NRP1-mediated PCa progression. Indeed, NRP1 can promote many aspects of tumorigenesis, such as angiogenesis, cell survival, migration, invasion and chemo-resistance. ${ }^{19,41,42}$ Further studies will be required to elucidate the contribution of various downstream signaling pathways to the aggressive phenotype mediated by NRP1 in the PCa setting. However, the therapeutic potential of targeting NRP1 has been highlighted by recent studies showing the blockade of NRP1 to inhibit the spread and growth of experimental models of human medulloblastoma, and non-small cell lung carcinoma xenografts. ${ }^{43,44}$

In conclusion, this study provides the first comprehensive clinical evaluation of NRP1 expression in human PCa. We have identified NRP1 at RP as a prognostic biomarker of shorter time to BCR, metastasis and cancer-specific mortality, and report that NRP1 functions to enhance the metastatic potential of PCa cells. We provide the first evidence that NRP1 expression is upregulated by ATTs, the standard clinical treatment for recurrent and metastatic disease. Collectively, our findings provide the preclinical data to support the use of anti-NRP1-targeted therapies as novel co-targeted therapies to be used in an adjuvant setting alongside current ATT and cytotoxic regimes in the treatment of men with advanced disease.

\section{MATERIALS AND METHODS}

Cell culture

LNCaP, DU145 and PC3 cells were sourced from the American Type Culture Collection (Manassas, VA, USA). C4-2B and BPH-1 cells were obtained from $\mathrm{Dr}$ Leland Chung, Cedars-Sinai Medical Center, Los Angeles, CA, USA, and Dr Simon Hayward, Vanderbilt University Medical Center, Nashville, TN, USA, respectively. LNCaP-Al cells were obtained from Dr Ralph Buttyan, Vancouver Prostate Centre, Vancouver, BC, Canada. All cell lines undergo mycoplasma testing on a quarterly basis. LNCaP, DU145, PC3, C4-2B, BPH-1 and LNCaP-Al cells were grown in RPMI medium with $10 \%$ FBS. LAPC4 cells were cultured in Iscove's modification of Dulbecco's medium with 10\% FBS. RWPE-1 cells were grown in keratinocyte medium containing recombinant human epidermal 
a

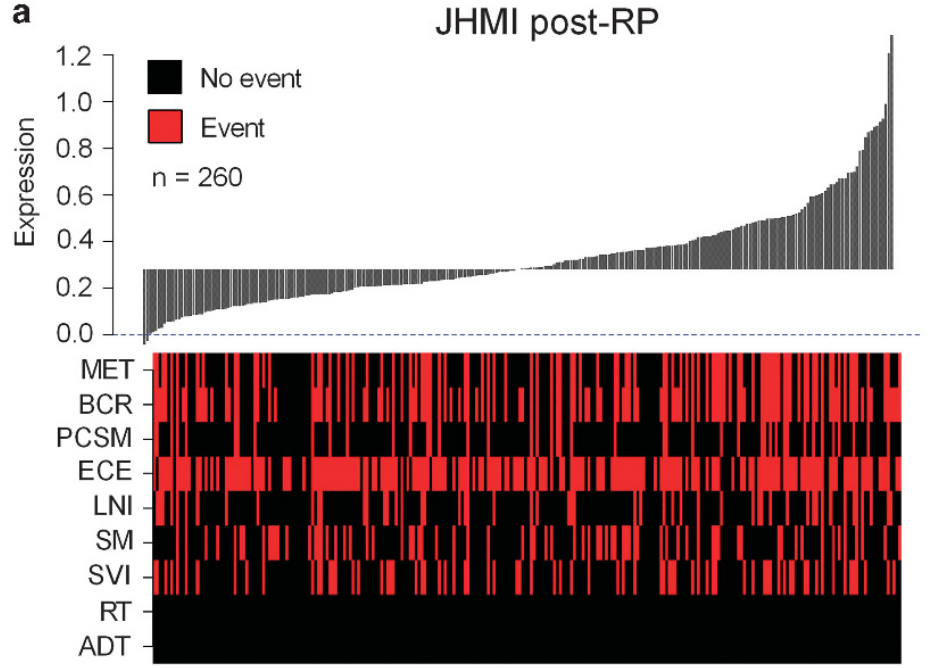

b

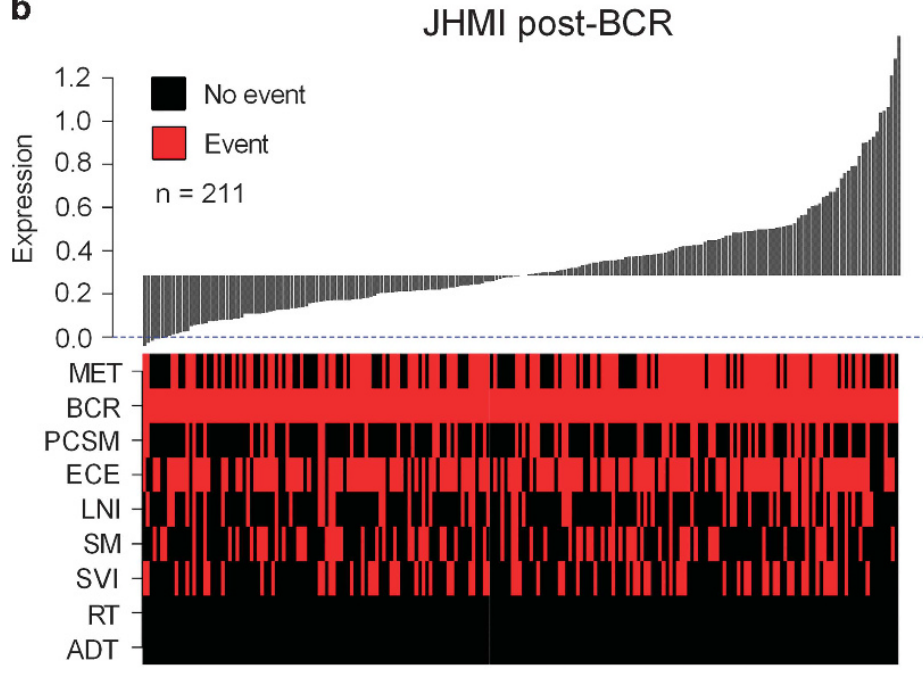

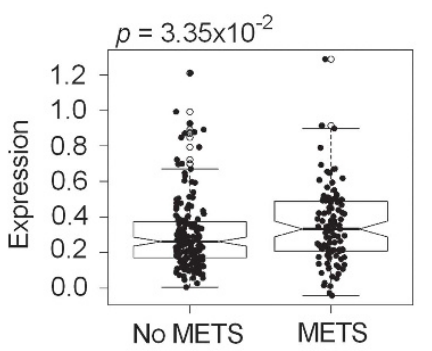
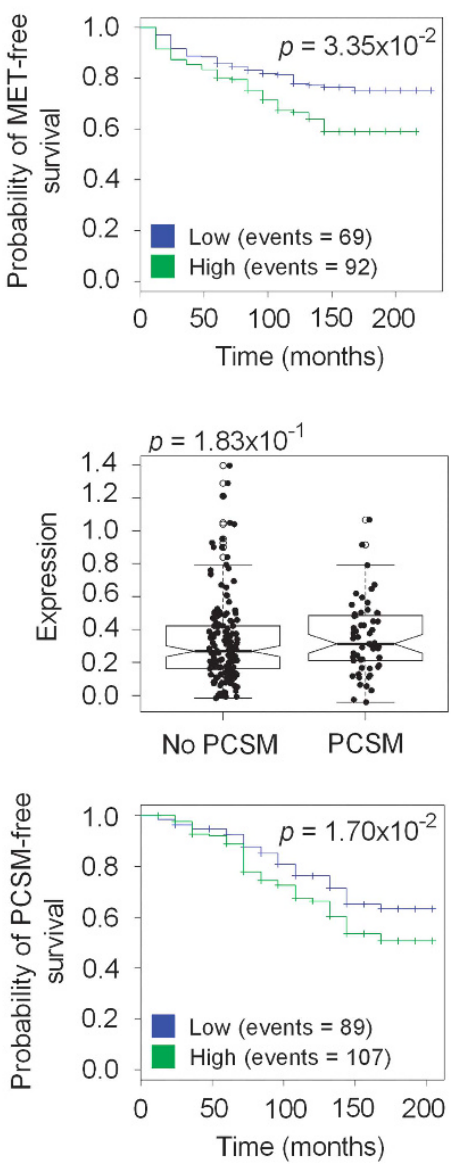

Figure 7. High NRP1 expression in RP samples is prognostic of metastatic progression and cancer-specific mortality in a natural history cohort. Waterfall plots showing NRP1 expression in JHMI patient cohorts in (a) post-RP and (b) post-BCR samples. Each sample is annotated in the colored matrix below the plot. ECE, extra-capsular extension; LNI, lymph node invasion; MET, metastasis; SM, surgical margin; SVI, seminal vesicle invasion. Boxplots showing NRP1 expression in patients positive and negative for METS (a) and PCSM (b). Kaplan-Meier curves showing MET-free (a) and PCSM-free (b) survival for NRP1 high and low expression groups.

growth factor $(5 \mathrm{ng} / \mathrm{ml})$ and bovine pituitary extract $(50 \mathrm{ng} / \mathrm{ml})$. shRNAtransfected PC3 and DU145 cells were maintained in an additional $1 \mu \mathrm{g} / \mathrm{ml}$ puromycin,

\section{Androgen and anti-androgen treatments}

LNCaP cells were seeded into six-well dishes at $9 \times 10^{4}$ cells per well in growth medium before medium was replaced with RPMI containing $5 \%$ CSS $72 \mathrm{~h}$ later. After $48 \mathrm{~h}$, medium was replaced with fresh RPMI/5\% CSS and cells were treated with $10 \mu \mathrm{m}$ ENZ or Bic (Selleck Chemicals, Houston, TX, USA) in the presence of $10 \mathrm{~nm}$ DHT or ethanol vehicle control, and RNA was harvested after $48 \mathrm{~h}$. For AR knockdown, LNCaP cells were cultured in growth medium for $72 \mathrm{~h}$ before being transiently transfected with $A R$ On-target Plus siRNA (target sequence 5'-CGAGAGAGCUGCAUCAGUU-3', GE Dharmacon, GE Healthcare, Lafayette, CO, USA) or nonspecific control small interfering RNA (GE Dharmacon, GE Healthcare) at a final concentration of $50 \mathrm{~nm}$ using Lipofectamine 2000 (Thermo Fisher Scientific, Waltham, MA, USA). Medium was replaced $48 \mathrm{~h}$ post-transfection with $\mathrm{RPMI} / 5 \% \mathrm{CSS}$, with or without $10 \mathrm{nM} \mathrm{DHT}$, and RNA collected $48 \mathrm{~h}$ later.
NRP1 shRNA knockdown

NRP1 shRNA pLKO.1 lentiviral vectors with mature anti-sense sequences 5'AATACTAATGTCATCCACAGC-3' (shNRP1(1)) and 5'-ATATAAGTGCATT CAAGGCTG-3' (shNRP1(2)), as well as a control sequence targeting firefly luciferase (sh(ntrl), were obtained from Thermo Fisher Scientific. Viral particles were produced as previously described. ${ }^{45}$

Evaluation of NRP1 protein expression in clinical PCa tissues A Gleason grade tissue microarray comprising 176 PCa patient samples was obtained from the Vancouver Prostate Centre Tissue Bank (see Supplementary Table 2 for a summary of clinicopathological features). Specimens were obtained from patients following informed consent using a protocol approved by the Clinical Research Ethics Board of the University of British Columbia and the BC Cancer Agency. Tissue microarray construction, IHC using a rabbit monoclonal antibody against human NRP1 (EPR3113, 2621-1, Epitomics, Burlingame, CA, USA) and evaluation of staining intensity were performed as previously described. ${ }^{46}$ 


\section{Quantitative PCR}

Total RNA was extracted with the RNeasy Mini Kit (Qiagen, Hilden, Germany) before reverse transcription with SuperScript III Reverse Transcriptase (Thermo Fisher Scientific). Quantitative PCR was performed using SYBR Green (Applied Biosystems, Foster City, CA, USA) using ViiA 7 or 7900 HT Fast Real Time PCR systems (Applied Biosystems). Gene expression was determined by the comparative Ct method, and normalized to the housekeeping gene RPL32. Primer sequences are shown in Supplementary Table 4.

\section{Analysis of Mayo Clinic, JHMI and TJU cohorts}

Affymetrix Human Exon 1.0 ST arrays were used to analyze NRP1 expression in RP samples derived from Mayo Clinic (GSE46691), JHMP ${ }^{31}$ and TJU (GSE72291) repositories (545, 644 and 130 patients, respectively). Within the JHMl repository, 361 patients who were positive for BCR post-RP were analyzed. Patient clinical characteristics and sample preparation methods have been described previously. ${ }^{30,31}$ Data were normalized and summarized using the SCAN algorithm. For grouped analysis, samples were split by the median expression of NRP1 into groups of low and high expression. The prognostic value of NRP1 was evaluated using multivariable odds ratios, and area under the receiver operating characteristics curve for $B C R$, metastasis and PCSM endpoints. Metastatic progression was defined by a positive bone or computed tomography scan. Kaplan-Meier survival analysis curves were generated for the JHMI cohorts but not for the Mayo cohort because of its nested case-control study design. All studies analyzed adhered to the PRoBE and REMARK guidelines for blinded evaluation and analysis of prognostic biomarkers. ${ }^{47,48}$

\section{Zebrafish metastasis assays}

Research was carried in accordance with protocols compliant with the Canadian Council on Animal Care and with the approval of the Animal Care Committee at the University of British Columbia. Wild-type zebrafish were maintained in aquaria according to standard protocols. ${ }^{49}$ Embryos were generated by natural pair-wise matings and raised at $28.5^{\circ} \mathrm{C}$ on a $14-\mathrm{h}$ light/10-h dark cycle in a $100 \mathrm{~mm}^{2}$ Petri dish containing aquarium water. In all, $0.2 \mathrm{~mm}$ phenylthiourea was added to the embryos at $10 \mathrm{~h}$ after fertilization to prevent pigment formation. ${ }^{50}$

PC3 cells were fluorescently labeled $24 \mathrm{~h}$ before microinjection with $1.5 \mu \mathrm{M}$ CellTracker CM-Dil dye (Thermo Fisher Scientific) according to the manufacturer's instructions. Wild-type embryos were dechorionated at 2 days after fertilization. Following tricane anesthetization, 50-70 cancer cells were microinjected into the yolk sacs of 50 animals per treatment group. Embryos were transferred to $100 \mathrm{~mm}^{2}$ dishes that contained aquaria water with added phenylthiourea. Embryos were visually assessed for presence of xenografts and only successfully xenografted embryos were included in the experiment. Embryos were kept at $35^{\circ} \mathrm{C}$ for the duration of the experiment. Metastatic dissemination outside the yolk sac was assessed 5 days later by observation using the Zeiss (Oberkochen, Germany) Axio Observer microscope with Zen 2012 software (Carl Zeiss Microscopy GmbH, Jena, Germany). Fixed cells were used as a control to ensure that observed metastasis was not due to yolk sac absorption.

\section{Flow cytometry}

Cells were grown to $80 \%$ confluence, washed twice in phosphatebuffered saline and detached using non-enzymatic cell dissociation buffer (Sigma Aldrich, St Louis, MO, USA). After washing and resuspension $\left(10^{6}\right.$ cells $\left./ \mathrm{ml}\right)$ in phosphate-buffered saline $/ 5 \%$ FBS, $100 \mu \mathrm{l}$ of cell suspension was incubated with anti-human NRP1-APC (\#446921) or mouse IgG2a Isotype Control-APC (\#20102) (R\&D Systems, Minneapolis, $M N, U S A)$ for $1 \mathrm{~h}$ on ice, then washed three times in phosphate-buffered saline $/ 5 \%$ FBS. Propidium iodide $(3 \mu \mathrm{l}, 100 \mu \mathrm{g} / \mathrm{ml}$ ) was added to the cells immediately before loading on a FACS Canto (BD Bioscience, Franklin Lakes, NJ, USA) to allow for viable cell gating. Data analysis was performed using Kaluza (Beckman Coulter, Brea, CA, USA) or Flowjo (Flowjo LLC, Ashland, OR, USA) software.

\section{Western blotting and immunofluorescence}

Western blotting was performed as described previously. ${ }^{45}$ Primary antibodies used were NRP1 (\#sc-7239, Santa Cruz, Dallas, TX, USA), AR (\#D6F11, Cell Signaling Technology, Danvers, MA, USA) and GAPDH (\#14C10, Cell Signaling Technology).
Invasion and proliferation assays

3D Laminin-rich Extracellular Matrix (IrECM) On-Top Cultures (referred to as 3D On-top Matrigel assays) were performed with an initial seeding density of $1 \times 10^{3}$ PC3 cells per well of a $96-$ well plate and conducted as previously. ${ }^{45}$ For invasion assays, 15000 PC3 or 25000 DU145 cells were seeded overnight into Matrigelcoated $(100 \mu \mathrm{g} / \mathrm{ml}$ in growth media) wells in a 96-well Image-lock plate (Essen BioScience Inc., Ann Arbor, Ml, USA). Wounds were made through the monolayer of confluent cells using the 96-pin WoundMaker (Essen BioScience Inc.) according to the manufacturer's instructions. Wells were washed twice with phosphate-buffered saline and matrigel $(50 \mu \mathrm{l}, 1 \mathrm{mg} / \mathrm{ml}$ in growth media) was added to each well and allowed to solidify before the initiation of imaging. Images were captured every $2 \mathrm{~h}$ for up to $48 \mathrm{~h}$ by the IncuCyte FLR live cell imaging system (Essen BioSciences Inc.). Wound closure kinetics were determined using the CellPlayer software module (Essen BioScience Inc.). For proliferation assays, cells were seeded as described for invasion assays and cell confluence determined using the same software. Proliferation was also assessed using the Quant-iT PicoGreen dsDNA Assay Kit (Thermo Fisher Scientific).

\section{Statistical analysis}

Data analysis was performed by one-way analysis of variance with Tukey's post hoc test for multiple comparisons, unless otherwise stated. Zebrafish metastasis assay results were analyzed by chi-square test. Statistical significance was defined as $P<0.05$. For publicly available microarray expression data sets, the normalized expression data for NRP1 was downloaded from the Oncomine database. Kaplan-Meier survival curve and log rank tests were performed using GraphPad Prism v6 software (GraphPad Software, Inc., San Diego, CA, USA).

\section{CONFLICT OF INTEREST}

The authors declare no conflict of interest.

\section{ACKNOWLEDGEMENTS}

We thank Dr Leland Chung and Dr Simon Hayward for kindly providing the C4-2B and $\mathrm{BPH}-1$ cell lines, respectively, used in this study. This research was supported by Cure Cancer Australia Foundation, Prostate Cancer Foundation of Australia and Cancer Australia PdCCRS grant 108878 and the Australian Government Department of Health, Queensland Government National and International Research Alliance Program funding to the Australian-Canadian Prostate Cancer Research Alliance, as well as by the Movember Foundation and the Prostate Cancer Foundation of Australia through a Movember Revolutionary Team Award.

\section{REFERENCES}

1 Heidenreich A, Bastian PJ, Bellmunt J, Bolla M, Joniau S, van der Kwast T et al. EAU guidelines on prostate cancer. Part II: treatment of advanced, relapsing, and castration-resistant prostate cancer. Eur Urol 2014; 65: 467-479.

2 de Bono JS, Oudard S, Ozguroglu M, Hansen S, Machiels JP, Kocak I et al. Prednisone plus cabazitaxel or mitoxantrone for metastatic castration-resistant prostate cancer progressing after docetaxel treatment: a randomised openlabel trial. Lancet 2010; 376: 1147-1154.

3 Tannock IF, de Wit R, Berry WR, Horti J, Pluzanska A, Chi KN et al. Docetaxel plus prednisone or mitoxantrone plus prednisone for advanced prostate cancer. $N$ Engl J Med 2004; 351: 1502-1512.

4 Sweeney CJ, Chen YH, Carducci M, Liu G, Jarrard DF, Eisenberger M et al. Chemohormonal therapy in metastatic hormone-sensitive prostate cancer. $\mathrm{N}$ Engl J Med 2015; 373: 737-746.

5 James ND, Sydes MR, Clarke NW, Mason MD, Dearnaley DP, Spears MR et al. Addition of docetaxel, zoledronic acid, or both to first-line long-term hormone therapy in prostate cancer (STAMPEDE): survival results from an adaptive, multiarm, multistage, platform randomised controlled trial. Lancet 2016; 387: 1163-1177.

6 Karantanos T, Corn PG, Thompson TC. Prostate cancer progression after androgen deprivation therapy: mechanisms of castrate resistance and novel therapeutic approaches. Oncogene 2013; 32: 5501-5511.

7 Locke JA, Guns ES, Lubik AA, Adomat HH, Hendy SC, Wood CA et al. Androgen levels increase by intratumoral de novo steroidogenesis during progression of castration-resistant prostate cancer. Cancer Res 2008; 68: 6407-6415.

8 Yuan X, Cai C, Chen S, Chen S, Yu Z, Balk SP. Androgen receptor functions in castration-resistant prostate cancer and mechanisms of resistance to new agents targeting the androgen axis. Oncogene 2014; 33: 2815-2825. 
9 Qi J, Tripathi M, Mishra R, Sahgal N, Fazli L, Ettinger S et al. The E3 ubiquitin ligase Siah2 contributes to castration-resistant prostate cancer by regulation of androgen receptor transcriptional activity. Cancer Cell 2013; 23: 332-346.

10 Ettinger SL, Sobel R, Whitmore TG, Akbari M, Bradley DR, Gleave ME et al. Dysregulation of sterol response element-binding proteins and downstream effectors in prostate cancer during progression to androgen independence. Cancer Res 2004; 64: 2212-2221.

11 Grasso CS, Wu YM, Robinson DR, Cao X, Dhanasekaran SM, Khan AP et al. The mutational landscape of lethal castration-resistant prostate cancer. Nature 2012; 487: 239-243.

12 Chandran UR, Ma C, Dhir R, Bisceglia M, Lyons-Weiler M, Liang W et al. Gene expression profiles of prostate cancer reveal involvement of multiple molecular pathways in the metastatic process. BMC Cancer 2007; 7: 64.

13 Taylor BS, Schultz N, Hieronymus H, Gopalan A, Xiao Y, Carver BS et al. Integrative genomic profiling of human prostate cancer. Cancer Cell 2010; 18: 11-22.

14 Vanaja DK, Cheville JC, Iturria SJ, Young CY. Transcriptional silencing of zinc finger protein 185 identified by expression profiling is associated with prostate cancer progression. Cancer Res 2003; 63: 3877-3882.

15 Varambally S, Yu J, Laxman B, Rhodes DR, Mehra R, Tomlins SA et al. Integrative genomic and proteomic analysis of prostate cancer reveals signatures of metastatic progression. Cancer Cell 2005; 8: 393-406.

16 Hansel DE, Wilentz RE, Yeo CJ, Schulick RD, Montgomery E, Maitra A. Expression of neuropilin-1 in high-grade dysplasia, invasive cancer, and metastases of the human gastrointestinal tract. Am J Surg Pathol 2004; 28: 347-356.

17 Hong TM, Chen YL, Wu YY, Yuan A, Chao YC, Chung YC et al. Targeting neuropilin 1 as an antitumor strategy in lung cancer. Clin Cancer Res 2007; 13: 4759-4768.

18 Latil A, Bieche I, Pesche S, Valeri A, Fournier G, Cussenot O et al. VEGF overexpression in clinically localized prostate tumors and neuropilin-1 overexpression in metastatic forms. Int J Cancer 2000; 89: 167-171.

19 Miao HQ, Lee P, Lin H, Soker S, Klagsbrun M. Neuropilin-1 expression by tumor cells promotes tumor angiogenesis and progression. FASEB J 2000; 14: 2532-2539.

20 Stephenson JM, Banerjee S, Saxena NK, Cherian R, Banerjee SK. Neuropilin-1 is differentially expressed in myoepithelial cells and vascular smooth muscle cells in preneoplastic and neoplastic human breast: a possible marker for the progression of breast cancer. Int J Cancer 2002; 101: 409-414.

21 Zhang S, Zhau HE, Osunkoya AO, lqbal S, Yang X, Fan S et al. Vascular endothelial growth factor regulates myeloid cell leukemia-1 expression through neuropilin-1dependent activation of c-MET signaling in human prostate cancer cells. $\mathrm{Mo}$ Cancer 2010; 9: 9.

22 Pomerantz MM, Li F, Takeda DY, Lenci R, Chonkar A, Chabot M et al. The androgen receptor cistrome is extensively reprogrammed in human prostate tumorigenesis. Nat Genet 2015; 47: 1346-1351.

23 Chen M, Feuerstein MA, Levina E, Baghel PS, Carkner RD, Tanner MJ et al. Hedgehog/Gli supports androgen signaling in androgen deprived and androgen independent prostate cancer cells. Mol Cancer 2010; 9: 89.

24 Best CJ, Gillespie JW, Yi Y, Chandramouli GV, Perlmutter MA, Gathright Y et al. Molecular alterations in primary prostate cancer after androgen ablation therapy. Clin Cancer Res 2005; 11(19 Pt 1): 6823-6834.

25 Robinson D, Van Allen EM, Wu YM, Schultz N, Lonigro RJ, Mosquera JM et al. Integrative clinical genomics of advanced prostate cancer. Cell 2015; 161: 1215-1228.

26 Peng Y, Liu YM, Li LC, Wang LL, Wu XL. MicroRNA-338 inhibits growth, invasion and metastasis of gastric cancer by targeting NRP1 expression. PLoS One 2014; 9: e94422.

27 Mak P, Leav I, Pursell B, Bae D, Yang X, Taglienti CA et al. ERbeta impedes prostate cancer EMT by destabilizing HIF-1alpha and inhibiting VEGF-mediated snail nuclear localization: implications for Gleason grading. Cancer Cell 2010; 17: 319-332.

28 Tsai JH, Yang J. Epithelial-mesenchymal plasticity in carcinoma metastasis. Genes Dev 2013; 27: 2192-2206.

29 Den RB, Feng FY, Showalter TN, Mishra MV, Trabulsi E, Lallas CD et al. Genomic prostate cancer classifier predicts biochemical failure and metastases in patients after postoperative radiation therapy. Int J Radiat Oncol Biol Phys 2014; 89: 1038-1046.

30 Erho N, Crisan A, Vergara IA, Mitra AP, Ghadessi M, Buerki C et al. Discovery and validation of a prostate cancer genomic classifier that predicts early metastasis following radical prostatectomy. PLoS One 2013; 8: e66855.

31 Ross AE, Johnson MH, Yousefi K, Davicioni E, Netto GJ, Marchionni L et al. Tissuebased genomics augments post-prostatectomy risk stratification in a natural history cohort of intermediate- and high-risk men. Eur Urol 2015.

32 Nouri M, Ratther E, Stylianou N, Nelson CC, Hollier BG, Williams ED. Androgentargeted therapy-induced epithelial mesenchymal plasticity and neuroendocrine transdifferentiation in prostate cancer: an opportunity for intervention. Front Oncol 2014; 4: 370.
33 Yuan X, Balk SP. Mechanisms mediating androgen receptor reactivation after castration. Urol Oncol 2009; 27: 36-41.

34 Sprenger CC, Plymate SR. The link between androgen receptor splice variants and castration-resistant prostate cancer. Horm Cancer 2014; 5: 207-217.

35 Lu J, Lonergan PE, Nacusi LP, Wang L, Schmidt LJ, Sun Z et al. The cistrome and gene signature of androgen receptor splice variants in castration resistant prostate cancer cells. J Urol 2015; 193: 690-698.

36 Teng Y, Xie X, Walker S, White DT, Mumm JS, Cowell JK. Evaluating human cancer cell metastasis in zebrafish. BMC Cancer 2013; 13: 453.

37 Patnaik A, LoRusso PM, Messersmith WA, Papadopoulos KP, Gore L, Beeram M et al. A phase lb study evaluating MNRP1685A, a fully human anti-NRP1 monoclonal antibody, in combination with bevacizumab and paclitaxel in patients with advanced solid tumors. Cancer Chemother Pharmacol 2014; 73: 951-960.

38 Glinka Y, Stoilova S, Mohammed N, Prud'homme GJ. Neuropilin-1 exerts coreceptor function for TGF-beta-1 on the membrane of cancer cells and enhances responses to both latent and active TGF-beta. Carcinogenesis 2011; 32: 613-621.

39 Patel P, West-Mays J, Kolb M, Rodrigues JC, Hoff CM, Margetts PJ. Platelet derived growth factor $B$ and epithelial mesenchymal transition of peritoneal mesothelial cells. Matrix Biol 2010; 29: 97-106.

40 West DC, Rees CG, Duchesne L, Patey SJ, Terry CJ, Turnbull JE et al. Interactions of multiple heparin binding growth factors with neuropilin-1 and potentiation of the activity of fibroblast growth factor-2. J Biol Chem 2005; 280: 13457-13464.

41 Jia H, Cheng L, Tickner M, Bagherzadeh A, Selwood D, Zachary I. Neuropilin-1 antagonism in human carcinoma cells inhibits migration and enhances chemosensitivity. Br J Cancer 2010; 102: 541-552.

42 Soker S, Miao HQ, Nomi M, Takashima S, Klagsbrun M. VEGF165 mediates formation of complexes containing VEGFR-2 and neuropilin-1 that enhance VEGF165-receptor binding. J Cell Biochem 2002; 85: 357-368.

43 Pan Q, Chanthery Y, Liang WC, Stawicki S, Mak J, Rathore N et al. Blocking neuropilin-1 function has an additive effect with anti-VEGF to inhibit tumor growth. Cancer Cell 2007; 11: 53-67.

44 Snuderl M, Batista A, Kirkpatrick ND, Ruiz de Almodovar C, Riedemann L, Walsh EC et al. Targeting placental growth factor/neuropilin 1 pathway inhibits growth and spread of medulloblastoma. Cell 2013; 152: 1065-1076.

45 Hollier BG, Tinnirello AA, Werden SJ, Evans KW, Taube JH, Sarkar TR et al. FOXC2 expression links epithelial-mesenchymal transition and stem cell properties in breast cancer. Cancer Res 2013; 73: 1981-1992.

46 Lin D, Dong X, Wang K, Wyatt AW, Crea F, Xue H et al. Identification of DEK as a potential therapeutic target for neuroendocrine prostate cancer. Oncotarget 2015; 6: 1806-1820.

47 McShane LM, Altman DG, Sauerbrei W, Taube SE, Gion M, Clark GM et al. REporting recommendations for tumour MARKer prognostic studies (REMARK). Eur J Cancer 2005; 41: 1690-1696.

48 Pepe MS, Feng $Z$, Janes H, Bossuyt PM, Potter JD. Pivotal evaluation of the accuracy of a biomarker used for classification or prediction: standards for study design. J Natl Cancer Inst 2008; 100: 1432-1438.

49 Westerfield M. The Zebrafish Book: A Guide for the Laboratory Use of Zebrafish (Danio Rerio). University of Oregon Press: Eugene, OR, USA, 1995.

50 Kimmel CB, Ballard WW, Kimmel SR, Ullmann B, Schilling TF. Stages of embryonic development of the zebrafish. Dev Dyn 1995; 203: 253-310.

51 Sun Y, Wang BE, Leong KG, Yue P, Li L, Jhunjhunwala $S$ et al. Androgen deprivation causes epithelial-mesenchymal transition in the prostate: implications for androgen-deprivation therapy. Cancer Res 2012; 72: 527-536.

52 Cerami E, Gao J, Dogrusoz U, Gross BE, Sumer SO, Aksoy BA et al. The cBio cancer genomics portal: an open platform for exploring multidimensional cancer genomics data. Cancer Discov 2012; 2: 401-404.

53 Gao J, Aksoy BA, Dogrusoz U, Dresdner G, Gross B, Sumer SO et al. Integrative analysis of complex cancer genomics and clinical profiles using the cBioPortal. Science Signal 2013; 6: p11.

(C) (i) $\Theta$ This work is licensed under a Creative Commons AttributionBY NC ND NonCommercial-NoDerivs 4.0 International License. The images or other third party material in this article are included in the article's Creative Commons license, unless indicated otherwise in the credit line; if the material is not included under the Creative Commons license, users will need to obtain permission from the license holder to reproduce the material. To view a copy of this license, visit http:// creativecommons.org/licenses/by-nc-nd/4.0/

(c) The Author(s) 2017 